\title{
Concomitant Medication Sequence Number
}

National Cancer Institute

\section{Source}

National Cancer Institute. Concomitant Medication Sequence Number. NCI Thesaurus.

Code $C 83233$.

An identifier that describes the relative position of concomitant medication data within a series. 